\title{
Associations Of Abnormalities Detected On Mri And Radiography With Hand Pain And Function In A Population-Based Older Adult Cohort.
}

\section{Siti Maisarah Mattap ( $\sim$ siti.mattap@utas.edu.au )}

Menzies Institute for Medical Research Tasmania https://orcid.org/0000-0002-8202-3083

\section{Karen Wills}

University of Tasmania Menzies Institute for Medical Research

\section{Dawn Aitken}

University of Tasmania Menzies Institute for Medical Research

\section{Andrew Halliday}

University of Tasmania Menzies Institute for Medical Research

\section{Shi-Nan Luong}

University of New South Wales

\section{Kathryn Squibb}

University of Tasmania Menzies Institute for Medical Research

\section{Flavia Cicuttini}

Monash University Department of Epidemiology and Preventive Medicine

\section{Graeme Jones}

University of Tasmania Menzies Institute for Medical Research

\section{Laura Laslett}

University of Tasmania Menzies Institute for Medical Research

\section{Research article}

Keywords: hand osteoarthritis, MRI, interphalangeal joint, hand pain, hand stiffness, hand function, AUSCAN

Posted Date: February 11th, 2020

DOI: https://doi.org/10.21203/rs.2.23194/v1

License: (c) (1) This work is licensed under a Creative Commons Attribution 4.0 International License.

Read Full License 


\section{Abstract}

Objective To describe associations between hand abnormalities on MRI or radiographs (X-ray) and pain and function in a cross-sectional study of community-based older adults.

Methods Distal and proximal interphalangeal index finger joints $(n=221)$ were examined using MRI, X-ray, and hand examination. Hand pain, function, and stiffness were assessed using Australian/Canadian hand osteoarthritis index (AUSCAN) questionnaire. Grip strength was assessed using dynamometer. Models were adjusted for age, sex, and other MRI or X-ray abnormalities.

Results Absence of collateral ligament (CLs) on MRI (relative risk; RR=3.15 (95\% confidence interval 1.33, 7.50), and joint space narrowing (JSN) on X-ray (RR=2.96 $(1.33,6.58))$ was associated with having a painful joint after adjustment for confounders. JSN was also associated with tender joints (RR=2.19 $(1.01,4.76))$. Effusion-synovitis was associated with better AUSCAN pain scores $(\mathrm{OR}=0.51(0.28,0.94))$ and JSN with worse AUSCAN pain scores (odds ratio; $\mathrm{OR}=1.67(1.13,2.48)$ ). Absent CLs were also associated with stiffer joints $(\mathrm{OR}=3.12(1.26,7.70))$ and weaker grip strength $(\beta=-1.69(-2.95,-0.43))$ independent of pain and other features; JSN was also associated with weaker grip strength ( $\beta=-0.87$ $(-1.62,-0.14))$. No other MRI or X-ray abnormalities were associated with pain or function independent of age, sex or pain.

Conclusion Most MRI abnormalities were not associated with pain and function cross-sectionally. Absent CLs and JSN were associated with painful joints and weak grip strength independent of pain and other imaging features. JSN was also associated with tender joints and absent CLs with stiff joints. Unexpectedly, effusions were associated with reduced odds of pain.

\section{Introduction}

Hand pain is extremely common in older adults [1, 2], and interferes with physical hand function $[3,4]$. Although radiography is routinely used to image hands, radiographic hand abnormalities are only weakly associated with pain and physical function limitation [5-8], and do not predict worsening of hand pain and function limitation $[9,10]$. MRI has advantages over conventional radiography as it gives threedimensional, multiplanar visualisation of all joint components and soft tissue changes, whereas conventional radiography (X-rays) provides a single image in two-dimension of bony changes and joint space width only.

Magnetic resonance imaging (MRI) is widely used to image knees, hips and spine osteoarthritis $(\mathrm{OA})$ in both clinical and research settings [11], but have rarely been used to image hands in hand osteoarthritis studies. Abnormal features of knee and hip joints seen on MRI such as bone marrow lesions (BMLs) and effusion-synovitis are associated with pain [12,13], poor physical function [14], structural progression or joint replacement [15], but there is limited data on associations between abnormal features seen on hand 
MRIs, and pain and function limitations $[16,17]$. The previous study demonstrated that bone marrow lesions (BMLs), synovitis, bone remodelling, and erosions were independently associated with joint tenderness, but not pain or function; while osteophytes were correlated with grip strength independent of age, sex, and other MRI abnormalities in people with hand OA (HOA) [16]. The previous studies were conducted in people with $\mathrm{OA}$, and no study has yet assessed the association in general older adult population.

Therefore, we aimed to describe cross-sectional associations between abnormalities present on MRI (effusion-synovitis, absence of collateral ligament (CL), BMLs, erosion, and osteophytes) or radiographs (osteophytes and joint space narrowing) with painful and tender joints, pain, physical function limitations, stiffness, and grip strength in a cohort of community dwelling older adults.

\section{Methods}

\section{Participants}

The Tasmanian older adult cohort (TASOAC) study is a prospective, population-based study which aimed to identify factors associated with development and progression of osteoarthritis and osteoporosis in older adults. Participants aged 50 and 80 years were recruited from the electoral roll in Southern Tasmania in 2002 using sex stratified random sampling (response rate 57\%). Participants were excluded if they lived in a nursing home or reported contraindications to MRI. Hand data (hand examination $(n=520), M R I(n=221)$, and X-ray ( $n=201))$ was only collected at the 10-year follow-up (2013 to 2015); therefore, analyses in this manuscript consists of cross-sectional data from the 10-year follow-up only $(n=221)$.

All research was conducted in compliance with the Declaration of Helsinki and was approved by the Southern Tasmanian Health and Medical Human Research Ethics Committee. All subjects gave informed written consent.

\section{Hand examination}

Bilateral clinical examination of the 15 joints of both hands were performed in all participants attending Phase 4 by one trained assessor (CB). Presence or absence of tenderness, soft tissue swelling, hard tissue enlargement (nodules) and deformity were assessed using American College of Rheumatology (ACR) criteria for HOA [18]. Tenderness was assessed by the examiner exerting pressure onto the joint using thumb and index finger sufficient to produce whitening of the examiners nail bed [19]. Joint pain in 
individual joints in the target hand was determined by asking participants if they had pain (yes/no) in each joint in the preceding seven days. Each patient's dominant hand (target hand) was imaged using radiographs and $\mathrm{MRI}$. If the participant had contraindications to MRI on the dominant hand, the contralateral hand was examined. Clinically defined HOA was diagnosed according to ACR criteria [18] using data from the clinical hand examination. Intra-observer reliability was assessed on 10 participants with at least a one-week interval between the readings using kappa-statistic [20]. The results were fair to substantial; $\mathrm{k}=0.376(95 \% \mathrm{Cl} 0.061,0.690)$ for left hand deformity, $\mathrm{k}=0.495(0.211,0.779)$ for left hand tenderness, $k=0.606(0.467,0.746)$ for left hand nodules, $k=0.668(0.537,0.799)$ for right hand nodules, and $k=0.688(0.431,0.946)$ for right hand deformity. Swollen and tender joints in the right hand, and swollen joints in the left hand had too little variability to enable kappa to be calculated.

\section{Hand pain, stiffness, physical function limitation, and total AUSCAN score.}

Pain was assessed as presence or absence of pain in a specific joint (proximal (PIP) or distal interphalangeal (DIP)) during clinical assessment, and hand pain (both hands) during the last 48 hours using Australian/Canadian hand osteoarthritis (AUSCAN) questionnaire [21] on 100mm visual analog scale (VAS) score. Hand stiffness and physical function were also assessed using the AUSCAN questionnaire; a 15 item questionnaire (5 for pain, 1 for (morning) stiffness, and 9 for physical function), which is a valid, reliable, and responsive measure for HOA [21].

AUSCAN subscales (hand pain, physical function limitation, and stiffness) scores and total AUSCAN scores are bounded by zero and non-normally distributed with a large number of zeros, therefore AUSCAN pain, stiffness, physical function limitation, and total AUSCAN scores were categorised into groups as none, below the median scores (mild to moderate), and above the median scores (moderate to severe). These equate to the following scores: pain score 0 (none), 1-51 (mild pain), and 52-500 (moderate to severe pain); stiffness score 0 (none), 1-12 (mild stiffness), and 13-100 (moderate to severe stiffness); physical function limitation score 0 (none), 1-73 (mild function limitation), and 74-900 (moderate to severe function limitation); total AUSCAN 0 (none), 1-111 (mild total disability), and 112-1500 (moderate to severe total disability).

\section{Magnetic resonance imaging (MRI)}

Distal interphalangeal (DIP) and proximal interphalangeal (PIP) joints of the index finger of the target hand were imaged using a 1.5T whole-body magnetic resonance unit (Siemens, Espree) using five sequences (supplementary Figure 1) with physical hand assessment and micro-computed tomography 
scans. One reader (SNL) assessed effusion-synovitis, absence of collateral ligaments (CLs), bone marrow lesions (BMLs), erosion, and osteophytes on T2-MRI sequences according to the Oslo Hand Osteoarthritis MRI score [22]. We did not use gadolinium contrast, and thus we cannot distinguish between effusion and synovitis. Therefore, we modified the scoring system to suit our MR images as follows:

Effusion-synovitis and CLs were scored as present or absent in either radius or ulnar (effusion-synovitis 1 $=$ present, 0 = absent $\mathrm{CL}$ absence/discontinuity present $=0$, absent $=1)$. BMLs, erosions, and osteophytes were classified on a $0-3$ scale at the distal and proximal of interphalangeal joints, $(0=$ none, $1=$ mild, 2=moderate, 3=severe). SNL re-scored 40 randomly selected MRI scans after 2 weeks and assessed intrareader reliability using kappa and weighted kappa. Intra-rater agreements were moderate to almost perfect [20] as shown in supplementary Table 1. Variability in DIP effusion, DIP and PIP absence of collateral ligament, and PIP osteophytes was too small to calculate kappa.

\section{Conventional radiography}

The target hand was also imaged using radiographs (X-ray). A single exposure anteroposterior radiograph of the hand was performed according to a standardised protocol [23]. JSN and osteophytes of the DIP and PIP index finger joints were independently assessed by 2 readers (KS and GJ). Severity of osteophytes and JSN were assessed using Osteoarthritis Research Society International (OARSI) atlas [23] using a 0-3 scale ( $0=$ normal, $1=$ mild change, $2=$ moderate change, $3=$ severe change). Intra-observer reliability was excellent for both osteophytes and JSN scores, assessed one week apart $(n=45)[8]$.

\section{Other factors}

BMI was calculated as weight $(\mathrm{kg}) /$ height $(\mathrm{m})^{2}$ using weight measured to the nearest $0.1 \mathrm{~kg}$ (with shoes, socks and bulky clothing removed) by calibrated electronic scales, and height measured to the nearest $0.1 \mathrm{~cm}$ (without shoes, socks and headwear) by stadiometer. Grip strength was measured using an adult bulb dynamometer (0-30 psi) (North Coast ${ }^{\mathrm{TM}}$ ) with the patient sitting with shoulders in a neutral position and the elbow in 90 degrees of flexion, the maximum value out of two attempts was used. In this study, we used grip strength measurements of the hand that had been imaged by MRI. Assessment of Quality of Life (AQoL-4D [24]) data from Phase 4 was used to assess participants quality of life over several domains. We used AQoL expressed as utility score, as such it is an index of the strength of a person's preference for a health state, with scores ranging from 0.00 (Dimension Worst Health State) to 1.00 (Dimension Best Health State). Any pain medication used were recorded in self-reported questionnaire from the list of medications they were taking (medication name, dose, and frequency). 


\section{Statistical analyses}

Associations with binary outcomes (presence of painful and tender joints) were assessed using log binomial regressions. Associations with categorical outcomes (categorical AUSCAN pain, physical function limitation, stiffness, and total AUSCAN score) were assessed using adjacent category ordinal logistic regressions. Associations with linear outcomes (grip strength) were assessed using linear regression. Models were adjusted for age and sex, and then further adjusted for pain (for function and grip strength outcomes) and then for all other MRI abnormalities or X-ray features to enable assessment

of confounders (age, sex, other MRI or X-ray features) and mediator (hand pain score on AUSCAN). All models had inverse probability weighting applied to adjust for study participants who were lost to followup. We conducted sensitivity analysis to examine whether pain medication use was a confounder. Further adjustment of all our presented models for any use of pain medication did not change the effect sizes by more than $10 \%$, therefore data not shown. All statistical analyses were performed using Stata $15 \mathrm{SE}$ (Stata-Corp, College Station, Texas, USA). The significant $p$-value was set at the value of less than 0.05 (two-tailed).

\section{Results}

Table 1 presents the characteristic of participants split by categorical AUSCAN pain scores. Greater proportions of participants with moderate to severe AUSCAN pain scores had weaker grip strength, met the ACR hand OA criteria, poorer quality of life, more joints which were painful and tender on clinical assessment, more joints with absent CLs on MRI, and greater JSN grade on X-ray compared to those with mild or no pain. Unexpectedly, effusion-synovitis was less common in those with moderate or mild pain. Half of participants with pain on AUSCAN were women compared to a third those with no pain.

There were no differences in the age, BMI, total MRI abnormalities mean score, presence of BML, erosion, and MRI and X-rays detected osteophytes amongst pain score groups.

\section{Painful and tender joints on clinical examination and AUSCAN pain}

Table 2 shows significant associations between absence of CLs and JSN and presence of painful joints after adjustment for age and sex and all other MRI features. JSN was also independently associated with higher risk of tender joints. Other MRI and X-ray features were not associated with either painful or tender joints. (Table 2). Further adjustment of the association between absence of CLs and painful joint for JSN on radiographs did not change effect sizes $(R R=2.75(1.08,7.00))$, indicating this effect was independent 
of JSN; however the reverse was not true (further adjustment of associations between JSN and painful joints for absent CLs $(\mathrm{RR}=2.24(0.83,6.03))$.

Table 3 shows that presence of effusion-synovitis was associated with increased odds of moving to a lower category of pain score (as assessed by AUSCAN pain score), after adjusting for age and sex and all other MRI abnormalities. Sensitivity analysis shows one or both DIP and PIP joints were associated with pain, with a threshold effect at one joint (data not shown). JSN was associated with increased odds of moving to a higher category of AUSCAN pain score, after adjustment for age and sex and other X-ray abnormalities (Table 3). Further adjusting the association between presence of effusion on MRI and AUSCAN pain for radiographic JSN did not significantly change the effect size ( $O R=0.50(0.25$ to 0.98$)$ ), and vice versa (JSN OR=1.68 (1.12 to 2.51)).

No other abnormalities were associated with AUSCAN pain score (Table 3).

\section{Physical function limitation, stiffness, and grip strength}

No abnormalities were associated with AUSCAN physical function limitation independent of AUSCAN pain and other imaging features (Table 3). Absent CLs is the only correlate of stiffness, independent of pain and other imaging features (Table 3). Absence of CLs and JSN were associated with weaker grip strength after adjustment for age, sex, pain, and all other MRI features (Table 4). Further adjustment of the association between absence of CLs and grip strength for JSN on radiographs did not change effect sizes ( $b=-1.63(-3.08$ to -0.18$)$ ), indicating this effect was independent of JSN; however not the reverse (further adjustment of associations between JSN and painful joints for absent CLs (JSN b=-0.68 (-1.42 to $0.06)$ ).

\section{Total AUSCAN score}

JSN is the only correlate of total AUSCAN score independent of age, sex and other imaging features (Supplementary Table 2).

\section{Discussion}


These results show that abnormal imaging features seen on hand MRI are common in older adults, both with and without pain. Absence of CLs were associated with greater risk of having a painful joint, stiffer hand with lower grip strength, while effusions were associated with lower risk of hand pain independent of other factors. However, presence of other abnormalities present on MRI and number of MRI abnormalities were not associated with joint pain, tenderness, or physical function limitation, stiffness, or grip strength independent of pain. JSN (on X-ray) was independently associated with joint pain, tenderness, and weaker grip strength. Overall, this demonstrates that absent CLs on MRI and JSN on hand radiographs are important correlates of hand pain in older adults.

Prevalence estimates of most abnormalities were comparable to estimates from existing literature, which is predominantly from cohorts of patients with HOA. Prevalence of effusion-synovitis was similar to two previous cohort of HOA patients $(54 \%$ to $98 \%)[17,25]$ but greater than reported by Haugen et al. $(13 \%)$, who used a different imaging method (contrast enhanced MRI to detect active synovitis (vs effusionsynovitis)) [26]. Similarly, prevalence of osteophytes on MRI was comparable with previous studies (34\% to $75 \%)[25,26]$. However, radiographic osteophytes were more common in our cohort than in the other two cohort studies (range 12\% to 33\%) [6, 27], but these studies included younger people over a wider age range than our study sample. Prevalence of erosions was similar to previous estimates 48\%, [16] but absent $\mathrm{CL}$ were rarer than estimates from cohorts of patients with $\mathrm{HOA}$ (range of $38 \%$ to $53 \%$ ) [22, 28]. Prevalence of JSN was higher in our cohort (37\%) than in a previous cohort study (12\% to $17 \%$ ) [27], but this may be attributable to use of different scoring systems (OARSI vs Kellgren and Lawrence).

This study is the first to report statistically significant associations between absence of CLs and painful hand joints, stiffer hands, and weak grip strength. Associations between absent CLs and increased pain is plausible as collateral ligaments have rich pain innervation in animal models and human knee joints, thus damaged collateral ligament may causes joint instability and pain during movement [29]. Ligament injury predicts radiographic knee $\mathrm{OA}$, pain, and function limitations over 12 years [30] and ligament tear is a risk factor in knee OA in young adults [31]. Thus, our data is consistent with data in knees, but not the only available data in hand joints: Haugen et al. found that absence of collateral ligaments was not correlated with AUSCAN pain and function limitation and grip strength [16], but reasons for the discrepancy are unclear.

Effusion-synovitis was common in our cohort, and effusion-synovitis of the knee joints are typically associated with knee pain [12, 32-34]. However, to the best of our knowledge, we are the first to show that presence of effusion-synovitis in the one hand joint is associated with lower AUSCAN hand pain scores. 
Ideally, presence of synovitis should be differentiated from effusion using contrast-enhanced MRI assessment, however, we elected not to do this as we did not consider that the increased risk of side effects from contrast agents was ethically justifiable in a research cohort. Thus, our findings need to be replicated in a cohort with contrast enhanced imaging.

Our study is the first to describe associations between MRI and radiograph detected abnormalities and stiffness. Absent CLs was the only significant correlate of stiffness.

We found no associations between osteophytes on MRI or X-ray and any outcome, whereas Kortekaas et al., found dose-dependent associations between osteophytes on X-ray with painful hand joints [35] and Haugen et al reported that osteophytes detected on MRI were the only independent correlates of low grip strength [16]. Reasons for these discrepancies are unclear. Additionally, we did not find associations between number of abnormalities on MRI and any clinical outcome, consistent with the literature [16].

Effusion-synovitis and JSN are two different and independent pathologies in the association with hand pain on AUSCAN. Associations between JSN and AUSCAN pain were independent of effusion-synovitis on MRI. However, associations between radiographic JSN and painful joints and grip strength were not independent of absent CLs on MRI, suggesting that absent CLs is a mediator in this association. Overall, absent CLs has a greater effect on the presence of pain and grip strength compared to JSN.

Overall, hand pain was associated with reduced hand function and grip strength in this data, which is consistent with the literature [35] [8]. When examining the associations between abnormal imaging features and physical function or grip strength, we adjusted for pain in order to assess whether these associations were independent. Of the imaging features seen on MRI, none were associated with physical function independent of age, sex and pain. Only absent CLs on MRI were associated with grip strength independent of age, sex, and pain. Since these associations are biologically plausible and consistent both across functional outcomes, and with similar reports in the knee [36, 37], this has the potential to be clinically relevant. JSN was also associated with reduced grip strength independent of pain, but smaller effect size than absence of CL. It is also independently associated with painful and tender joints, and AUSCAN pain score, consistent with previous studies $[35,38,39]$. This is plausible because normal cartilage is aneural, whilst abnormal cartilage is not [40,41]. Additionally, thinning cartilage could increase the effect of localised loading to the innervated subchondral bone [42], but given that hand X-ray abnormalities do not predict worsening of clinical outcomes (as outlined in the introduction), these crosssectional associations between JSN and pain and grip strength may not have strong clinical relevance. 
This study utilised three different ways of measuring pain (joint pain on palpation and tender joints during clinical assessment, and whole hand pain measured by AUSCAN questionnaire). We showed that painful joints on clinical examination and AUSCAN pain are more sensitive in measuring pain than tenderness. This might be due to poor reliability of tender joint assessment along with it being highly assessor dependent [43]. Therefore, future studies should include site-specific joint pain and whole hand pain measurement as outcomes. This study also assessed associations between osteophytes measured on both MRI and X-ray and clinical outcomes. Strength of associations were greater with presence of osteophytes on MRI and clinical outcomes, but osteophytes were not significantly associated with clinical outcomes regardless of imaging modality.

Strengths of this study include using standardised radiograph and MRI hand osteoarthritis atlases and the population-based source of the data; which enables findings to be generalised to older adults in the community. We also included three different pain measurements which improves confidence in the findings.

Limitations include loss to follow up within the TASOAC cohort: data used for this study (collected at the ten year follow up) is a subset of the original cohort that had MRI and X-ray images taken, who were younger, had lower BMI, and fewer females at baseline than those who did not complete the 10 year follow up ( $n=875$ ) (data not shown), but absolute differences were small. However, to account for these differences, we have inverse probability weighted the data; therefore, the results remain generalisable to older people. Other potential limitations include the small number of joints assessed - DIP and PIP of the index finger on one hand, rather than assessment of a whole hand, meaning that the prevalence of abnormalities and associations with pain and function could differ between these two joints and other hand joints. However, previous studies show that index finger DIP joints have the highest prevalence of symptomatic HOA, and index finger PIP joints have similar prevalence of symptomatic HOA to the other finger joints $[4,44]$. Therefore, the prevalence should be similar or slightly overestimated than if we assessed the whole hand. We were unable to assess the effect of not assessing all hand joints on associations between hand pain and function. Thumb base OA may be a larger contributor to poor function than the fingers we assessed, and had we assessed imaging abnormalities in the thumb, we may have found different associations. Also, we were unable to assess presence of BMLs at the collateral ligament enthesis, and effusion-synovitis was scored as present or absent in this study due to available image quality and without using gadolinium contrast medium. Thus, we cannot provide the prevalence of BMLs at the collateral ligament enthesis, and we may underestimate the effect size of the association between inflammation (detected by effusion-synovitis in this study), and hand pain and symptoms. 
In conclusion, most MRI abnormalities were not associated with pain and function cross-sectionally. Absent CLs and JSN were associated with painful joints and weak grip strength independent of pain and other imaging features. JSN was also associated with tender joint and absent CLs with stiff joints. Unexpectedly, effusions were associated with reduced odds of pain. Longitudinal population-based cohort studies are needed to confirm these findings.

\section{Declarations}

\section{Ethics approval and consent to participate}

All research conducted was in compliance with the Declaration of Helsinki and was approved by the Southern Tasmanian Health and Medical Human Research Ethics Committee. All subjects gave informed written consent.

\section{Consent for publication}

Not applicable

\section{Availability of data and material}

The datasets used and/or analysed during the current study are available from the corresponding author on reasonable request.

\section{Acknowledgements}

We thank the participants who made this study possible, and Catrina Boon (CB) and Pip Boon for their role in collecting the data.

\section{Author's contributions}

All authors were involved in drafting the article or revising it for important intellectual content. All authors have approved the final manuscript. Laura L. Laslett (laura.laslett@utas.edu.au) takes responsibility for the integrity of the work as a whole, from inception to finished article.

Conception and design: Mattap, Aitken, Wills, Jones, Laslett

Analysis and interpretation of data: Mattap, Wills, Aitken, Halliday, Luong, Squibb, Cicuttini, Jones, Laslett

Drafting of the article: Mattap, Laslett

Critical revision of the article for important intellectual content: Mattap, Wills, Aitken, Halliday, Luong, Squibb, Cicuttini, Jones, Laslett 
Final approval of the article: Mattap, Wills, Aitken, Halliday, Luong, Squibb, Cicuttini, Jones, Laslett

Statistical expertise: Wills

Obtaining of funding: Cicuttini, Jones

Collection and assembly of data: Luong, Halliday, Squibb, Jones, Mattap

\section{Role of funding source}

This work was supported by the National Health and Medical Research Council of Australia; Tasmanian Community Fund; Masonic Centenary Medical Research Foundation; Royal Hobart Hospital Research Foundation; and Arthritis Foundation of Australia. The study sponsor had no role in the design of the study; the collection, analysis, and interpretation of the data; or the writing of the article and the decision to submit it for publication.

SM Mattap is supported by the Farrell foundation elite postgraduate scholarship, G Jones and LL Laslett are supported by National Health and Medical Research Council. The researchers work independently of their funders.

Competing interest statement

The authors declare no competing interest.

\section{References}

1. Dahaghin S, Bierma-Zeinstra SMA, Reijman M, Pols HAP, Hazes JMW, Koes BW: Prevalence and determinants of one month hand pain and hand related disability in the elderly (Rotterdam study). Ann Rheum Dis 2005, 64(1):99-104.

2. Keenan A-m, Tennant A, Fear J, Emery P, Conaghan PG: Impact of multiple joint problems on daily living tasks in people in the community over age fifty-five. Arthritis Care Res (Hoboken) 2006, 55(5):757-764.

3. Slatkowsky-Christensen B, Mowinckel P, Loge JH, Kvien TK: Health-related quality of life in women with symptomatic hand osteoarthritis: a comparison with rheumatoid arthritis patients, healthy controls, and normative data. Arthritis Rheum 2007, 57(8):1404-1409.

4. Zhang Y, Niu J, Kelly-Hayes M, Chaisson CE, Aliabadi P, Felson DT: Prevalence of Symptomatic Hand Osteoarthritis and Its Impact on Functional Status among the ElderlyThe Framingham Study. Am J 
Epidemiol 2002, 156(11):1021-1027.

5. Dahaghin S, Bierma-Zeinstra SM, Ginai AZ, Pols HA, Hazes JM, Koes BW: Prevalence and pattern of radiographic hand osteoarthritis and association with pain and disability (the Rotterdam study). Ann Rheum Dis 2005, 64(5):682-687.

6. Hart D, Spector T, Egger P, Coggon D, Cooper C: Defining osteoarthritis of the hand for epidemiological studies: the Chingford Study. Ann Rheum Dis 1994, 53(4):220-223.

7. Haugen IK, Slatkowsky-Christensen B, Bøyesen P, van der Heijde D, Kvien TK: Cross-sectional and longitudinal associations between radiographic features and measures of pain and physical function in hand osteoarthritis. Osteoarthritis Cartilage 2013, 21(9):1191-1198.

8. Jones G, Cooley HM, Bellamy N: A cross-sectional study of the association between Heberden's nodes, radiographic osteoarthritis of the hands, grip strength, disability and pain. Osteoarthritis Cartilage 2001, 9(7):606-611.

9. Bijsterbosch J, Watt I, Meulenbelt I, Rosendaal FR, Huizinga TW, Kloppenburg M: Clinical and radiographic disease course of hand osteoarthritis and determinants of outcome after 6 years. Ann Rheum Dis 2011, 70(1):68-73.

10. Botha-Scheepers S, Riyazi N, Watt I, Rosendaal FR, Slagboom E, Bellamy N, Breedveld FC, Kloppenburg M: Progression of hand osteoarthritis over 2 years: a clinical and radiological follow-up study. Ann Rheum Dis 2009, 68(8):1260-1264.

11. Guermazi A, Burstein D, Conaghan P, Eckstein F, Hellio Le Graverand-Gastineau M-P, Keen H, Roemer FW: Imaging in Osteoarthritis. Rheumatic Disease Clinics of North America 2008, 34(3):645-687.

12. Yusuf E, Kortekaas MC, Watt I, Huizinga TWJ, Kloppenburg M: Do knee abnormalities visualised on MRI explain knee pain in knee osteoarthritis? A systematic review. Ann Rheum Dis 2011, 70(1):60-67.

13. Ahedi H, Dore D, Blizzard L, Cicuttini F, Jones G: A population based study of the association between hip bone marrow lesions and pain[abstr]. Intern Med J 2012, 42:25-26.

14. Davis MA, Ettinger WH, Neuhaus JM, Mallon KP: Knee osteoarthritis and physical functioning: evidence from the NHANES I Epidemiologic Followup Study. The Journal of rheumatology 1991, 18(4):591-598.

15. Mattap SM, Aitken D, Wills K, Laslett L, Ding C, Pelletier JP, Martel-Pelletier J, Graves SE, Lorimer M, Cicuttini F et al: How Do MRI-Detected Subchondral Bone Marrow Lesions (BMLs) on Two Different MRI Sequences Correlate with Clinically Important Outcomes? Calcif Tissue Int 2018, 103(2):131143.

16. Haugen IK, Bøyesen P, Slatkowsky-Christensen B, Sesseng S, van der Heijde D, Kvien TK: Associations between MRI-defined synovitis, bone marrow lesions and structural features and measures of pain and physical function in hand osteoarthritis. Ann Rheum Dis 2012, 71(6):899-904.

17. Kwok W-Y, Kortekaas MC, Reijnierse M, Heijde DAvd, Bloem JL, Kloppenburg M: MRI in hand osteoarthritis: Validation of the Oslo hand osteoarthritis MRI-scoring method and association with pain. Osteoarthritis Cartilage 2011(19 Suppl 1):S7-S52. 
18. Altman R, Alarcon G, Appelrouth D, Bloch D, Borenstein D, Brandt K, Brown C, Cooke TD, Daniel W, Gray $\mathrm{R}$ et al: The American College of Rheumatology criteria for the classification and reporting of osteoarthritis of the hand. Arthritis Rheum 1990, 33(11):1601-1610.

19. van Riel P, van Gestel A, Scott D: EULAR Handbook of Clinical Assessments in Rheumatoid Arthritis. Nijmegen; 2000.

20. Landis JR, Koch GG: The measurement of observer agreement for categorical data. Biometrics 1977, 33(1):159-174.

21. Bellamy N: Clinimetric properties of the AUSCAN Osteoarthritis Hand Index: an evaluation of reliability, validity and responsiveness. Osteoarthritis Cartilage 2002, 10.

22. Haugen IK, Lillegraven S, Slatkowsky-Christensen B, Haavardsholm EA, Sesseng S, Kvien TK, van der Heijde D, Bøyesen P: Hand osteoarthritis and MRI: development and first validation step of the proposed Oslo Hand Osteoarthritis MRI score. Ann Rheum Dis 2011, 70(6):1033-1038.

23. Altman RD, Gold GE: Atlas of individual radiographic features in osteoarthritis, revised. Osteoarthritis Cartilage 2007, 15(Supplement 1):A1-A56.

24. Hawthorne G, Richardson J, Osborne R: The Assessment of Quality of Life (AQoL) instrument: a psychometric measure of Health-Related Quality of Life. Qual Life Res 1999, 8(3):209-224.

25. Wittoek R, Jans L, Lambrecht V, Carron P, Verstraete K, Verbruggen G: Reliability and construct validity of ultrasonography of soft tissue and destructive changes in erosive osteoarthritis of the interphalangeal finger joints: a comparison with MRI. Ann Rheum Dis 2011, 70(2):278-283.

26. Haugen IK, Bøyesen P, Slatkowsky-Christensen B, Sesseng S, Bijsterbosch J, van der Heijde D, Kvien TK: Comparison of features by MRI and radiographs of the interphalangeal finger joints in patients with hand osteoarthritis. Ann Rheum Dis 2012, 71(3):345-350.

27. Sonne-Holm S, Jacobsen S: Osteoarthritis of the first carpometacarpal joint: a study of radiology and clinical epidemiology: Results from the Copenhagen Osteoarthritis Study. Osteoarthritis Cartilage 2006, 14(5):496-500.

28. Tan AL, Grainger AJ, Tanner SF, Shelley DM, Pease C, Emery P, McGonagle D: High-resolution magnetic resonance imaging for the assessment of hand osteoarthritis. Arthritis Rheum 2005, 52(8):2355-2365.

29. McDougall JJ, Bray RC, Sharkey KA: Morphological and immunohistochemical examination of nerves in normal and injured collateral ligaments of rat, rabbit, and human knee joints. The Anatomical Record 1997, 248(1):29-39.

30. Lohmander LS, Östenberg A, Englund M, Roos H: High prevalence of knee osteoarthritis, pain, and functional limitations in female soccer players twelve years after anterior cruciate ligament injury. Arthritis Rheum 2004, 50(10):3145-3152.

31. Roos EM: Joint injury causes knee osteoarthritis in young adults. Curr Opin Rheumatol 2005, 17(2):195-200.

32. Baker K, Grainger A, Niu J, Clancy M, Guermazi A, Crema M, Hughes L, Buckwalter J, Wooley A, Nevitt $\mathrm{M}$ et al: Relation of synovitis to knee pain using contrastenhanced MRIs. Ann Rheum Dis 2010, 
69(10):1779-1783.

33. Wang X, Jin X, Han W, Cao Y, Halliday A, Blizzard L, Pan F, Antony B, Cicuttini F, Jones G et al: Crosssectional and Longitudinal Associations between Knee Joint Effusion Synovitis and Knee Pain in Older Adults. J Rheumatol 2016, 43(1):121-130.

34. Hayashi D, Roemer FW, Dhina Z, Kwoh CK, Hannon MJ, Moore C, Guermazi A: Longitudinal assessment of cyst-like lesions of the knee and their relation to radiographic osteoarthritis and MRIdetected effusion and synovitis in patients with knee pain. Arthritis Res Ther 2010, 12(5):R172-R172.

35. Kortekaas MC, Kwok W-Y, Reijnierse M, Huizinga TWJ, Kloppenburg M: Osteophytes and joint space narrowing are independently associated with pain in finger joints in hand osteoarthritis. Ann Rheum Dis 2011, 70(10):1835-1837.

36. Kim HA, Kim I, Song YW, Kim DH, Niu J, Guermazi A, Crema MD, Hunter DJ, Zhang Y: The association between meniscal and cruciate ligament damage and knee pain in community residents. Osteoarthritis Cartilage 2011, 19(12):1422-1428.

37. Hill CL, Seo GS, Gale D, Totterman S, Gale ME, Felson DT: Cruciate ligament integrity in osteoarthritis of the knee. Arthritis Rheum 2005, 52(3):794-799.

38. Kwok WY, Bijsterbosch J, Malm SH, Biermasz NR, Huetink K, Nelissen RG, Meulenbelt I, Huizinga TWJ, van 't Klooster R, Stoel BC et al: Validity of joint space width measurements in hand osteoarthritis. Osteoarthritis Cartilage 2011, 19(11):1349-1355.

39. Wen L, Shin M-H, Kang J-H, Yim Y-R, Kim J-E, Lee J-W, Lee K-E, Park D-J, Kim T-J, Kweon S-S et al: Association between grip strength and hand and knee radiographic osteoarthritis in Korean adults: Data from the Dong-gu study. PLoS One 2017, 12(11):e0185343-e0185343.

40. Walsh DA, McWilliams DF, Turley MJ, Dixon MR, Fransès RE, Mapp PI, Wilson D: Angiogenesis and nerve growth factor at the osteochondral junction in rheumatoid arthritis and osteoarthritis. Rheumatology (Oxford) 2010, 49(10):1852-1861.

41. Wojtys EM, Beaman DN, Glover RA, Janda D: Innervation of the human knee joint by substance-P fibers. Arthroscopy 1990, 6(4):254-263.

42. Hunter DJ, March L, Sambrook PN: The association of cartilage volume with knee pain. Osteoarthritis Cartilage 2003, 11(10):725-729.

43. Hart LE, Tugwell P, Buchanan WW, Norman GR, Grace EM, Southwell D: Grading of tenderness as a source of interrater error in the Ritchie articular index. $J$ Rheumatol 1985, 12(4):716-717.

44. Slatkowsky-Christensen B, Haugen IK, Kvien TK: Distribution of joint involvement in women with hand osteoarthritis and associations between joint counts and patient-reported outcome measures. Ann Rheum Dis 2010, 69(01):198-201.

\section{Tables}

Table 1. Characteristic of participants, by AUSCAN pain score $(n=221)$. 


\begin{tabular}{|c|c|c|c|c|c|c|}
\hline & AUSC & $\begin{array}{l}\text { p pain } \\
\text { pain score }=0 \\
\end{array}$ & AUS & $\begin{array}{l}\text { ild pain } \\
\text { ain score }=1-50 \\
n=65\end{array}$ & \multicolumn{2}{|c|}{$\begin{array}{c}\text { Moderate - severe pain } \\
\text { AUSCAN pain score }>51-500 \\
n=62\end{array}$} \\
\hline Age & \multicolumn{2}{|c|}{$72.3(6.4)$} & \multicolumn{2}{|c|}{$71.3(6.4)$} & \multicolumn{2}{|c|}{$73.1(7.2)$} \\
\hline Female (\%) & \multicolumn{2}{|r|}{32} & \multicolumn{2}{|r|}{52} & \multicolumn{2}{|c|}{55} \\
\hline BMI $\left(\mathrm{kg} / \mathrm{m}^{2}\right)$ & \multicolumn{2}{|c|}{$27.9(4.3)$} & \multicolumn{2}{|c|}{$27.3(4.5)$} & \multicolumn{2}{|c|}{$28(4.1)$} \\
\hline Grip Strength (psi) & \multicolumn{2}{|c|}{$12.2(3.4)$} & \multicolumn{2}{|c|}{$11.6(3.8)$} & \multicolumn{2}{|c|}{$9(3.6)$} \\
\hline Hand OA (ACR criteria) & \multicolumn{2}{|c|}{39.4} & \multicolumn{2}{|r|}{69.2} & \multicolumn{2}{|c|}{91.9} \\
\hline Total MRI abnormalities mean score (1-22) & & $5(2.8)$ & & $.0(3.1)$ & \multicolumn{2}{|c|}{$5.8(3.9)$} \\
\hline \multirow[t]{2}{*}{ AQoL utility score } & \multicolumn{2}{|c|}{$0.8(0.19)$} & \multicolumn{2}{|c|}{$0.78(0.16)$} & \multicolumn{2}{|c|}{$0.66(0.19)$} \\
\hline & $\%$ & $\begin{array}{l}\text { No. of joints } \\
\qquad(0-2)\end{array}$ & $\%$ & $\begin{array}{l}\text { No. of joints } \\
(0-2)\end{array}$ & $\%$ & $\begin{array}{c}\text { No. of } \\
\text { joints } \\
(0-2)\end{array}$ \\
\hline \multicolumn{7}{|l|}{ Clinical Assessment } \\
\hline Painful joints & 0 & $0(0)$ & 2 & $0(0.1)$ & 33 & $0.4(0.6)$ \\
\hline Tender joints & 1 & $0(0.1)$ & 5 & $0.1(0.3)$ & 28 & $0.3(0.6)$ \\
\hline \multicolumn{7}{|l|}{ MRI assessment } \\
\hline Effusion-synovitis & 95 & $1.4(0.6)$ & 91 & $1.4(0.7)$ & 85 & $1.4(0.7)$ \\
\hline $\begin{array}{l}\text { Absence of } \\
\text { collateral ligament }\end{array}$ & 4 & $0(0.2)$ & 2 & $0(0.1)$ & 13 & $0.1(0.4)$ \\
\hline BML & 60 & $0.8(0.7)$ & 63 & $0.9(0.8)$ & 69 & $0.9(0.7)$ \\
\hline Erosion & 38 & $0.5(0.7)$ & 34 & $0.5(0.7)$ & 45 & $0.6(0.8)$ \\
\hline Osteophytes & 69 & $0.8(0.6)$ & 82 & $1(0.6)$ & 81 & $1(0.6)$ \\
\hline $\begin{array}{l}\text { No. of MRI } \\
\text { abnormalities }\end{array}$ & 100 & $2.7(1.13)$ & 98 & $2.7(1.1)$ & 98 & $3(1.2)$ \\
\hline \multicolumn{7}{|l|}{ Radiographic assessment } \\
\hline Osteophytes & 67 & $0.9(0.7)$ & 73 & $1(0.7)$ & 71 & $1(0.8)$ \\
\hline JSN & 28 & $0.3(0.5)$ & 35 & $0.4(0.6)$ & 50 & $0.6(0.7)$ \\
\hline
\end{tabular}

Mean (standard deviation) except for percentage.

Clinical, MRI, and radiographic assessment are presence of the features at either distal or proximal interphalangeal joint of the same MRI target hand.

n, number; BMI, body mass index; AUSCAN, Australian/Canadian hand osteoarthritis index; MRI, magnetic resonance imaging; ACR, American College of Rheumatology; AQoL, Assessment of Quality of Life; CL, collateral ligament; BML, bone marrow lesions; JSN, joint space narrowing.

Table 2. Associations of MRI/X-ray abnormalities and painful or tender index finger joints on clinical examination. 


\begin{tabular}{|c|c|c|c|c|}
\hline \multirow[b]{2}{*}{ Adjusted for } & \multicolumn{2}{|c|}{ Presence of painful joint } & \multicolumn{2}{|c|}{ Presence of tender joint } \\
\hline & $\begin{array}{l}\text { age and sex } \\
\text { RR (95\% CI) }\end{array}$ & $\begin{array}{c}\text { + all other MRI/X-ray } \\
\text { abnormalities } \\
\text { RR }(95 \% \mathrm{CI})\end{array}$ & $\begin{array}{l}\text { age and sex } \\
\text { RR (95\% CI) }\end{array}$ & $\begin{array}{c}\text { + all other MRI/X-ray } \\
\text { abnormalities } \\
\text { RR }(95 \% \mathrm{CI})\end{array}$ \\
\hline \multicolumn{5}{|c|}{ MRI abnormalities... } \\
\hline Effusion & $\begin{array}{c}0.82(0.21 \\
3.25)\end{array}$ & $0.60(0.15,2.46)$ & $0.66(0.20,2.20)$ & $0.59(0.15,2.33)$ \\
\hline Absence of CL & $\begin{array}{c}5.22(2.47 \\
11.04)\end{array}$ & $3.15(1.33,7.50)$ & $0.80(0.12,5.25)$ & $0.65(0.08,5.13)$ \\
\hline BML & $\begin{array}{c}3.10(0.91 \\
10.55)\end{array}$ & $1.16(0.21,6.45)$ & $1.01(0.95,1.07)$ & $1.15(0.31,4.18)$ \\
\hline Erosion & $\begin{array}{c}3.40(1.42, \\
8.15)\end{array}$ & $2.34(0.65,8.43)$ & $1.01(0.95,1.07)$ & $1.31(0.42,4.05)$ \\
\hline Osteophytes & $\begin{array}{c}6.13(0.88 \\
42.94)\end{array}$ & $3.33(0.42,26.16)$ & $1.44(0.40,5.24)$ & $1.20(0.27,5.34)$ \\
\hline $\begin{array}{c}\text { No. of MRI } \\
\text { abnormalities }\end{array}$ & $\begin{array}{c}3.36(0.78 \\
14.50)\end{array}$ & - & $1.04(0.43,2.54)$ & - \\
\hline \multicolumn{5}{|c|}{ X-ray abnormalities... } \\
\hline Osteophytes & $\begin{array}{c}0.88(0.36 \\
2.16)\end{array}$ & $0.71(0.31,1.65)$ & $1.00(0.38,2.63)$ & $0.86(0.35,2.12)$ \\
\hline JSN & $\begin{array}{c}2.83(1.23 \\
6.49)\end{array}$ & $2.96(1.33,6.58)$ & $2.15(0.95,4.87)$ & $2.19(1.01,4.76)$ \\
\hline
\end{tabular}

Associations were assessed using log binomial regression with inverse probability weighting.

No. of MRI abnormalities were dichotomised at the median (3).

MRI, magnetic resonance imaging; RR, relative risk; CI, confidence interval; CL, collateral ligament; BML, bone marrow lesions; JSN, joint space narrowing.

Bold denotes a statistically significant result.

Table 3. Associations of MRI/X-ray abnormalities at index finger and AUSCAN pain, function limitation, and stiffness. 


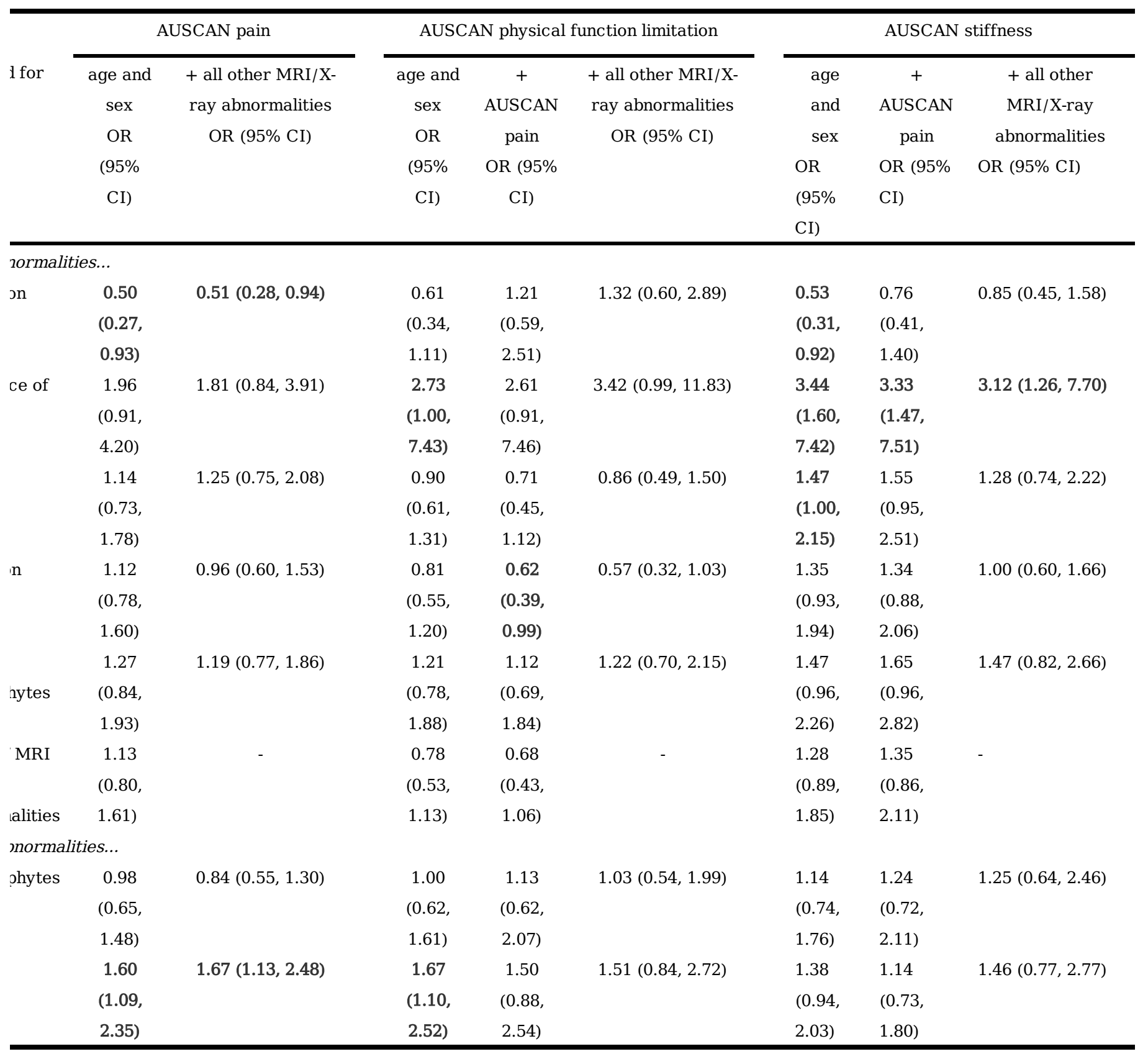

Associations were assessed using ordinal logistic regression with inverse probability weighting.

AUSCAN scales were categorised as none, below, and above median.

No. of MRI abnormalities were dichotomised at the median (3).

AUSCAN, Australian/Canadian hand osteoarthritis index; OR, odds ratio; CI, confidence interval; MRI, magnetic resonance imaging; RR, relative risk; CI, confidence interval; CL, collateral ligament; BML, bone marrow lesions; JSN, joint space narrowing.

Bold denotes a statistically significant result.

Table 4. Associations of presence of MRI/X-ray abnormalities at the index finger joints and grip strength. 


\begin{tabular}{|c|c|c|c|}
\hline \multirow[b]{2}{*}{ Adjusted for } & \multicolumn{3}{|c|}{ Grip strength (0-30psi) } \\
\hline & $\begin{array}{l}\text { age and sex } \\
\beta(95 \% \mathrm{CI})\end{array}$ & $\begin{array}{c}+ \text { AUSCAN pain } \\
\beta(95 \% \mathrm{CI})\end{array}$ & $\begin{array}{c}+ \text { all MRI/-ray abnormalities } \\
\beta(95 \% \mathrm{CI})\end{array}$ \\
\hline \multicolumn{4}{|c|}{ MRI abnormalities... } \\
\hline Effusion & $0.95(-0.58,2.48)$ & $0.48(-0.93,1.89)$ & $0.47(-0.94,1.89)$ \\
\hline Absence of CL & $-2.04(-3.20,-0.88)$ & $-1.56(-2.79,-0.34)$ & $-1.69(-2.95,-0.43)$ \\
\hline BML & $-0.10(-0.89,0.69)$ & $-0.03(-0.76,0.70)$ & $-0.02(-0.92,0.87)$ \\
\hline Erosion & $-0.14(-0.85,0.57)$ & $-0.04(-0.69,0.61)$ & $0.08(-0.66,0.82)$ \\
\hline Osteophytes & $0.48(-0.31,1.27)$ & $0.48(-0.25,1.22)$ & $0.66(-0.16,1.48)$ \\
\hline $\begin{array}{l}\text { No. of MRI } \\
\text { abnormalities }\end{array}$ & $-0.04(-0.83,0.75)$ & $0.01(-0.72,0.73)$ & - \\
\hline \multicolumn{4}{|c|}{$X$-ray abnormalities... } \\
\hline Osteophytes & $-0.20(-0.99,0.59)$ & $-0.21(-0.95,0.53)$ & $0.03(-0.77,0.84)$ \\
\hline JSN & $-1.08(-1.82,-0.34)$ & $-0.87(-1.54,-0.19)$ & $-0.87(-1.61,-0.14)$ \\
\hline
\end{tabular}

Associations were assessed using linear regression with inverse probability weighting.

Number of MRI abnormalities were dichotomised at the median (3).

MRI, magnetic resonance imaging; $\beta$, beta-coefficient; CI, confidence interval; CL, collateral ligament; BML, bone marrow lesions; JSN, joint space narrowing.

Bold denotes a statistically significant result.

\section{Supplementary Files}

This is a list of supplementary files associated with this preprint. Click to download.

- SupplementarytablesMRIXray.docx 